\title{
Comparison of Machine Learning Techniques for the Prediction of Compressive Strength of Concrete
}

\author{
Palika Chopra $\mathbb{D}^{1},{ }^{1}$ Rajendra Kumar Sharma, ${ }^{1}$ Maneek Kumar $\mathbb{D}^{2},{ }^{2}$ and Tanuj Chopra $\mathbb{D}^{2}$ \\ ${ }^{1}$ Department of Computer Science and Engineering, Thapar University, Patiala, India \\ ${ }^{2}$ Department of Civil Engineering, Thapar University, Patiala, India \\ Correspondence should be addressed to Palika Chopra; palika.chopra@thapar.edu
}

Received 27 August 2017; Revised 3 December 2017; Accepted 15 January 2018; Published 12 April 2018

Academic Editor: Pier Paolo Rossi

Copyright (C) 2018 Palika Chopra et al. This is an open access article distributed under the Creative Commons Attribution License, which permits unrestricted use, distribution, and reproduction in any medium, provided the original work is properly cited.

\begin{abstract}
A comparative analysis for the prediction of compressive strength of concrete at the ages of 28,56 , and 91 days has been carried out using machine learning techniques via " $\mathrm{R}$ " software environment. $\mathrm{R}$ is digging out a strong foothold in the statistical realm and is becoming an indispensable tool for researchers. The dataset has been generated under controlled laboratory conditions. Using $\mathrm{R}$ miner, the most widely used data mining techniques decision tree (DT) model, random forest (RF) model, and neural network $(\mathrm{NN})$ model have been used and compared with the help of coefficient of determination $\left(R^{2}\right)$ and root-mean-square error (RMSE), and it is inferred that the NN model predicts with high accuracy for compressive strength of concrete.
\end{abstract}

\section{Introduction}

Concrete is a widely used construction material which is the mixture of cement $(c)$, water $(w)$, fine aggregates (sand), and coarse aggregates (ca) and used almost for decades in every kind of structures, either it is roadways or buildings. The structures which have sufficient strengths may be unsafe due to errors involved in reinforcement design of the structure, the environmental conditions which can degrade the concrete, and so on. The safety of a structure is not determined by the compressive strength of the concretes only, although it does affect the safety to a large extent. However, the information about input values is never certain and/or absolute because of randomness, limited knowledge, and incorrect information. All these factors are responsible for the unpredictability of in-place strength of material produced, incorrect formulation of mathematical prediction models, and human errors. With this kind of information, it is very difficult to estimate the absolute safety of a structure which could lead to risks associated with the performance of the structure. Many researchers have made efforts to overcome these risks and develop models which can evaluate the performance of the structure before the start of any project [1-12]. The literature of the prediction of the compressive strength of concrete reveals a number of traditional and looming models for the same, but in most of the studies, the database had been prepared from data available in literature only, and in the present study, the dataset has been generated under controlled laboratory conditions and also previously published in [13]. Research studies presented in [14-18]. show some of the important regression models currently available in literature for prediction of compressive strength of concrete. Sayed-Ahmed [16] developed a statistical model to predict compressive strength of concrete containing different matrix mixtures at fixed age or at different ages of $1,3,7,28,56,91$, and 180 days. He concluded that the predicted model had a high correlation to the experimental results for the concrete compressive strength. Topcu and Saridemir [19] developed a model for predicting the compressive strength of concrete containing fly ash using neural network (NN) and fuzzy logic (FL). For the purpose of constructing these models, they gathered 52 different mixes with 180 specimens from the literature. They claimed that both of these models can predict at great accuracy level. Basyigit et al. [20] predicted the compressive strength of heavy weight concrete by NN and FL models and concluded 
that compressive strength can be estimated using developed models of NN and FL without performing any more experiments. Wankhade and Kambekar [21] developed a data mining approach to predict the compressive strength and assessed the prediction reliability for the high-performance concrete. They reported that NN can be looked upon an alternative approach in prediction of concrete compressive strength. Tiryaki and Aydin [22] designed the NN model to predict compressive strength parallel to grain of heat-treated woods, without doing compressive experiments. They also compared NN with multiple linear regression (MLR). The results of their study indicated that NN provided a better prediction as compared to the MLR. Nikoo et al. [23] developed the $\mathrm{NN}$ model for the purpose of constructing models, samples of cylindrical concrete parts with different characteristics were used with 173 experimental data patterns, and the compressive strength of concrete had been calculated. They recommended that the NN model enjoyed more accuracy, flexibility, capability, and accuracy in predicting the compressive strength of concrete. Khademi et al. [24] developed and compared three different models: MLR, $\mathrm{NN}$, and adaptive neuro-fuzzy inference system (ANFIS), to predict compressive strength of concrete at the age of 28 days. They reported that NN and ANFIS models yielded reliable results, and MLR was not feasible because of the nonlinear relationship between the concrete mix parameters. Khashman and Akpinar [25] developed the NN model to predict and classify the compressive strength of concrete mixes into low, moderate, and high strength and concluded that the results of the study showed high efficiency in correctly classifying the compressive strength. Chopra et al. [11] used the trial and error method to reach at the best suitable architecture possible for NN; whereas it is effortless to select the precise architecture using Chopra et al. [13] who developed a NN model and compared it with Genetic Programming (GP) model. It was observed that NN model performed better as compared to GP model. In the present study, the aim is to compare the NN model with DT and RF models to further ensure its competence for the prediction of compressive strength of concrete using database of [11-13] at the ages of 28, 56, and 91 days.

\section{Experimental Dataset}

Table 1 shows the variations in the values of parameters, and the dataset have been selected for concrete compressive strength analysis is in Table 2 (published in [11-13]; generated by Kumar [26]).

The concrete mixes have been proportioned for different values of parameters, which affect compressive strength of concrete. The $w$ requirement for each zone of aggregate has been selected based upon the workability requirement. The proportions for various concrete mixes have been obtained by varying $w / c, w, c$ and sand. The workability of designed mixes lied in the slump range of $50 \mathrm{~mm}$ to $100 \mathrm{~mm}$. The DoE method of mix design was used for determining the proportions. Various adjustments due to variations in the specific gravity, water absorption, and so on were also incorporated in the design. The details of
TABLE 1: Range of values of various parameters.

\begin{tabular}{lc}
\hline Water-cementitious $(w / c)$ ratio & $0.42-0.55$ \\
Cement content $(c)$ & $350-475 @ 25 \mathrm{~kg} / \mathrm{m}^{3}$ \\
Water content $(w)$ & $180-230 @ 10 \mathrm{~kg} / \mathrm{m}^{3}$ \\
Workability & $50-100 \mathrm{~mm} \mathrm{slump}$ \\
Curing ages (days) & $28,56,91$ \\
\hline
\end{tabular}

the proportions for concrete mixes and the details of the compressive strength data at 28-, 56-, and 91-day curing ages for these mixes are presented in Table 2. The tuples of the dataset have been further divided into training set, validation set, and testing set. Training set contains $70 \%$ data of respective dataset; validation set contains 15\%; and testing dataset also contains $15 \%$ of data of the respective dataset.

\section{Methods}

In the present study, three models have been used for the prediction of compressive strength of concrete: (i) decision tree (DT) model, (ii) random forest (RF) model, and (iii) neural network (NN) model.

3.1. Decision Tree Model. The first model is the DT model (Algorithm 1). It is popular in literature due to its suppleness to model higher order nonlinearity and greater interpretability [27, 28]. The DT model splits data into smaller subsets in the form of tree structure. There are three types of nodes in DT: (i) root node (RN) (ii) decision node (DN), and (iii) leaf node (LN). The top most node is RN. At DN, a conditional test is conducted, and further subtrees are decided according to the outcome of the test. $\mathrm{LN}$ is the target node (output) of the tree. DT algorithms calculate two types of entropies (a measure of homogeneity of the dataset) [29]:

(a) Entropy using the frequency table of one attribute

$$
E(D)=\sum_{k=1}^{c}-p_{k} \log _{2} p_{k},
$$

where $p_{k}$ is the proportion of $D$ belonging to class $k$.

(b) Entropy using the frequency table of two attributes

$$
E(T, X)=\sum_{c \in X} P(c) E(c),
$$

where $T$ is the target attribute, $X$ is the decision attribute, $c$ is the tuple values of attribute $X, P(c)$ is the probability of occurrence of $c$, and $E(c)$ is the entropy of $c$.

Next step is to calculate the decrease in the entropy or information gain.

$$
\operatorname{Gain}(T, X)=E(T)-E(T, X),
$$

where $T$ is the target attribute, $X$ is the decision attribute, $c$ is the tuple values of attribute $X, E(T)$ is the calculated entropy of the target attribute, and $E(T, X)$ is the entropy of $X$ tuples in $T$ attribute. 
TABLE 2: Details of proportions and compressive strength for concrete mixes after curing of 28, 56, and 91 days.

\begin{tabular}{|c|c|c|c|c|c|c|c|}
\hline Serial number & Mix designation & $w / c$ ratio & $\begin{array}{l}\text { Mix proportions } \\
\text { (c: sand: ca) }\end{array}$ & $\begin{array}{c}\text { Cement content, } \\
c\left(\mathrm{Kg} / \mathrm{m}^{3}\right)\end{array}$ & 28 days $(\mathrm{MPa})$ & 56 days $(\mathrm{MPa})$ & 91 days $(\mathrm{MPa})$ \\
\hline 1 & MD-1 & 0.53 & $1: 1.58: 3.048$ & 375 & 36.84 & 40.92 & 44.52 \\
\hline 2 & MD-2 & 0.50 & $1: 1.43: 2.824$ & 400 & 43.13 & 50.22 & 51.97 \\
\hline 3 & MD-3 & 0.53 & $1: 1.54: 2.993$ & 400 & 38.58 & 45.51 & 47.49 \\
\hline 4 & $\mathrm{MD}-4$ & 0.47 & $1: 1.27: 2.575$ & 425 & 47.16 & 51.25 & 54.27 \\
\hline 5 & MD-5 & 0.49 & $1: 1.39: 2.773$ & 425 & 45.05 & 50.72 & 52.85 \\
\hline 6 & MD-6 & 0.44 & $1: 1.14: 2.352$ & 450 & 49.63 & 54.48 & 58.04 \\
\hline 7 & MD-7 & 0.47 & $1: 1.25: 2.541$ & 450 & 47.42 & 51.34 & 55.30 \\
\hline 8 & MD-8 & 0.42 & $1: 1.05: 2.194$ & 475 & 54.01 & 57.91 & 60.15 \\
\hline 9 & MD-9 & 0.44 & $1: 1.19: 2.463$ & 475 & 50.05 & 55.72 & 58.31 \\
\hline 10 & MD-10 & 0.53 & $1: 1.58: 3.048$ & 375 & 37.81 & 43.50 & 47.55 \\
\hline 11 & MD-11 & 0.50 & $1: 1.43: 2.824$ & 400 & 44.11 & 50.98 & 52.56 \\
\hline 12 & MD-12 & 0.53 & $1: 1.54: 2.993$ & 400 & 40.90 & 46.56 & 51.07 \\
\hline 13 & MD-13 & 0.47 & $1: 1.27: 2.575$ & 425 & 47.51 & 52.92 & 54.47 \\
\hline 14 & MD-14 & 0.49 & $1: 1.397: 2.77$ & 425 & 45.30 & 51.47 & 53.09 \\
\hline 15 & MD-15 & 0.51 & $1: 1.51: 2.946$ & 425 & 42.54 & 49.05 & 51.19 \\
\hline 16 & MD-16 & 0.44 & $1: 1.14: 2.352$ & 450 & 52.03 & 56.26 & 59.19 \\
\hline 17 & MD-17 & 0.47 & $1: 1.25: 2.541$ & 450 & 48.74 & 53.42 & 55.03 \\
\hline 18 & MD-18 & 0.49 & $1: 1.37: 2.730$ & 450 & 46.59 & 53.21 & 53.67 \\
\hline 19 & MD-19 & 0.42 & $1: 1.05: 2.193$ & 4750 & 54.49 & 58.65 & 63.07 \\
\hline 20 & MD-20 & 0.44 & $1: 1.19: 2.462$ & 475 & 53.06 & 56.67 & 62.57 \\
\hline 21 & MD-21 & 0.46 & $1: 1.23: 2.510$ & 475 & 49.18 & 54.04 & 57.10 \\
\hline 22 & MD-22 & 0.52 & $1: 1.426: 2.02$ & 425 & 40.02 & 46.92 & 48.48 \\
\hline 23 & MD-23 & 0.49 & $1: 1.288: 1.86$ & 450 & 45.25 & 50.43 & 53.09 \\
\hline 24 & MD-24 & 0.51 & $1: 0.393: 1.98$ & 450 & 42.68 & 48.54 & 49.63 \\
\hline 25 & MD-25 & 0.46 & $1: 1.167: 1.71$ & 475 & 48.67 & 53.48 & 56.50 \\
\hline 26 & MD-26 & 0.48 & $1: 1.264: 1.83$ & 475 & 45.52 & 50.97 & 53.63 \\
\hline 27 & MD-27 & 0.51 & $1: 1.392: 3.25$ & 350 & 39.52 & 43.31 & 46.13 \\
\hline 28 & MD-28 & 0.54 & $1: 1.497: 3.42$ & 350 & 31.66 & 37.18 & 43.92 \\
\hline 29 & MD-29 & 0.48 & $1: 1.245: 2.98$ & 375 & 42.73 & 48.23 & 52.23 \\
\hline 30 & MD-30 & 0.51 & $1: 1.354: 3.18$ & 375 & 40.69 & 44.46 & 46.42 \\
\hline 31 & MD-31 & 0.45 & $1: 1.10: 2.703$ & 400 & 47.99 & 52.95 & 55.51 \\
\hline 32 & MD-32 & 0.48 & $1: 1.21: 2.915$ & 400 & 44.89 & 51.20 & 53.85 \\
\hline 33 & MD-33 & 0.42 & $1: 0.98: 2.468$ & 425 & 51.25 & 57.55 & 59.50 \\
\hline 34 & MD-34 & 0.45 & $1: 1.08: 2.677$ & 425 & 49.05 & 54.14 & 57.35 \\
\hline 35 & MD-35 & 0.42 & $1: 0.97: 2.454$ & 450 & 53.69 & 57.77 & 59.89 \\
\hline 36 & MD-36 & 0.54 & $1: 1.49: 3.424$ & 350 & 36.64 & 43.46 & 46.55 \\
\hline 37 & MD-37 & 0.51 & $1: 1.35: 3.185$ & 375 & 41.57 & 46.81 & 50.04 \\
\hline 38 & MD-38 & 0.48 & $1: 1.21: 2.915$ & 400 & 46.22 & 52.58 & 53.07 \\
\hline 39 & MD-39 & 0.45 & $1: 1.09: 2.677$ & 425 & 50.35 & 56.02 & 58.32 \\
\hline 40 & MD-40 & 0.42 & $1: 0.98: 2.454$ & 450 & 54.11 & 58.52 & 62.28 \\
\hline 41 & MD-41 & 0.53 & $1: 1.43: 2.412$ & 375 & 37.30 & 43.51 & 46.63 \\
\hline 42 & MD-42 & 0.50 & $1: 1.32: 2.211$ & 400 & 44.04 & 50.53 & 52.55 \\
\hline 43 & MD- 43 & 0.53 & $1: 1.44: 2.364$ & 400 & 39.61 & 46.09 & 48.17 \\
\hline 44 & MD-44 & 0.47 & $1: 1.19: 2.032$ & 425 & 47.37 & 51.31 & 54.77 \\
\hline 45 & MD-45 & 0.49 & $1: 1.29: 2.175$ & 425 & 44.69 & 50.69 & 52.75 \\
\hline 46 & MD-46 & 0.44 & $1: 1.07: 1.856$ & 450 & 50.93 & 55.71 & 59.05 \\
\hline 47 & MD-47 & 0.47 & $1: 1.17: 2.003$ & 450 & 48.08 & 52.63 & 55.61 \\
\hline 48 & MD-48 & 0.42 & $1: 0.95: 1.681$ & 475 & 54.14 & 58.21 & 61.11 \\
\hline 49 & MD-49 & 0.44 & $1: 1.06: 1.841$ & 475 & 51.31 & 56.37 & 59.51 \\
\hline
\end{tabular}




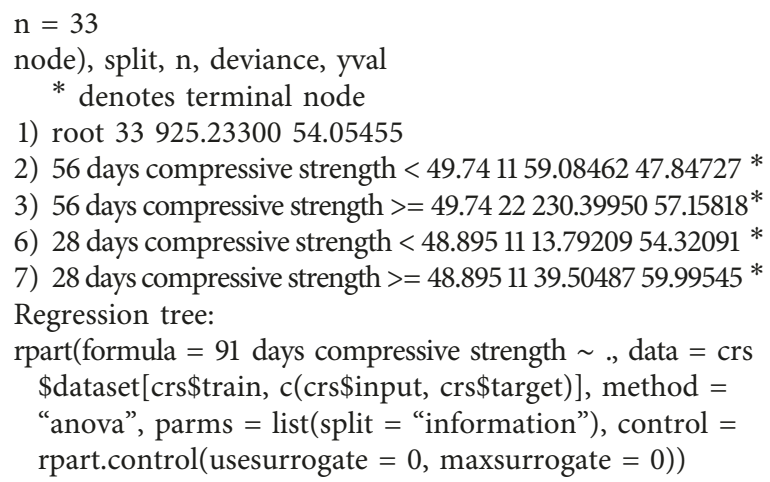

Algorithm 1: Summary of DT model architecture for CLASSIFICATION [39].

The information gain of each branch of the dataset is calculated; then the attribute with the largest information gain is chosen as the decision node and a branch with gain 0 is a leaf node. The algorithm runs recursively on the nonleaf branches, until all the data are classified [39].

3.2. Random Forest Model. The second model used, in the study, is the RF model for the prediction of compressive strength (Algorithm 2). The RF model is an ensemble classification approach and recently received attention from many researchers [30, 31]. Shaqadan [32] used the RF model for the prediction of compressive strength of concrete. The difference between DT and RF is that in DT only one tree is constructed; however, in case of the RF model, numbers of trees have been constructed, and via an ensemble process, the final class is decided. This set of a number of trees is called a forest; a different data frame is randomly selected and assigned to each tree. The data frame is the dimensions of rows and columns, and for every tree, different subset of rows and columns has been selected [39]. Each tree is grown with the following steps:

(i) The first step is to select the data frame. The data frame is $2 / 3$ of the total training data selected randomly for each tree. This is known as bagging. Predictor variables are selected randomly, and the best split on these variables is used to split the node.

(ii) For each tree, calculate the out-of-bag error (validation or testing) using the rest of the data. Then, errors from all the trees are aggregated to find the overall out-of-bag error rate.

(iii) Each tree gives a classification, and the model chooses from the forest having most of the votes over all the trees in the forest. The votes could be 0 's or 1's. The percentage of 1's received is defined as the prediction probability.

3.3. Neural Network Model. The third model used, in this study, is NN (Algorithm 3). The application of NN model has been used in the field of civil engineering for more than
Number of observations used to build the model: 33 Missing value imputation is active.

Call:

RandomForest (formula $=91$ days compressive strength $\sim$., data $=$ crs $\$$ dataset $[$ crs $\$$ sample, $c($ crs $\$$ input, crs\$target $)]$, ntree $=500$, mtry $=2$, importance $=$ TRUE, replace $=$ FALSE, na.action $=$ randomForest::na.roughfix)

Type of RF: regression

Number of trees: 500

No. of variables tried at each split: 2

Mean of squared residuals: 2.360152

\% Var explained: 91.58

Algorithm 2: Summary of RF model architecture [39].

three decades $[8,33,34]$. NN consists of the following three principal elements [35]:

(i) Organization of layers and their interconnection with other layers of the network, that is, topology.

(ii) Techniques to store information in the network, that is, learning.

(iii) Methods to retrieve information from the network, that is, recall.

The most common NN structure consists of an input layer, one or more hidden layers, and an output layer [36]. The NNs considered for empirical investigation in this study are also one of the hidden layer networks with a single output. For elaboration purposes, let the input dimension be $n\left(n \in Z_{+}\right)$ and let the number of hidden neurons be $m\left(m \in Z_{+}\right)$. The training pairs are represented by $D=\left\{\mathbf{x}^{(p)}, t^{(p)}\right\}$, where $p=1,2, \ldots, P ; P \in Z_{+}$, is the number of training exemplars, and the index $p$ is always assumed to be present implicitly. The matrix $w$ denotes the input to the hidden neurons connection strength, $w_{i j}$ is the $(i, j)$ th element of the matrix $w$ representing the connection strength between the $j$ th input and the $i$ th hidden layer neuron [39]. With this nomenclature, the net input to the $i$ th hidden layer neuron is given by

$$
\text { net }_{i}=\sum_{j=1}^{n} w_{i j} x_{j}+\theta_{i}^{(1)}=\mathbf{w}_{i} \cdot \mathbf{x}+\theta_{i}^{(1)},
$$

where $\theta_{i}^{(1)}$ is the bias of the $i$ th hidden layer neuron. The output from the $i$ th hidden layer neuron is given by

$$
h_{i}(\mathbf{x})=f^{(1)}\left(\text { net }_{i}\right) \text {, }
$$

where $f^{(1)}(\cdot)$ is a nonlinear activation function. The equation for the network output neuron is given by

$$
\text { net }_{o}=f^{(2)}(\text { net })=\text { net, }
$$

as $f^{(2)}(\cdot)$ has been considered as a linear function in this study.

Such a NN is trained to fit a dataset $\mathrm{D}$ by minimizing an error function (or performance function) as

$$
F=E_{D}(\mathbf{W})=\frac{1}{P} \sum_{p=1}^{P} \varepsilon^{2}=\frac{1}{P} \sum_{p=1}^{P}\left(\text { net }_{o}^{(p)}-t^{(p)}\right)^{2} .
$$




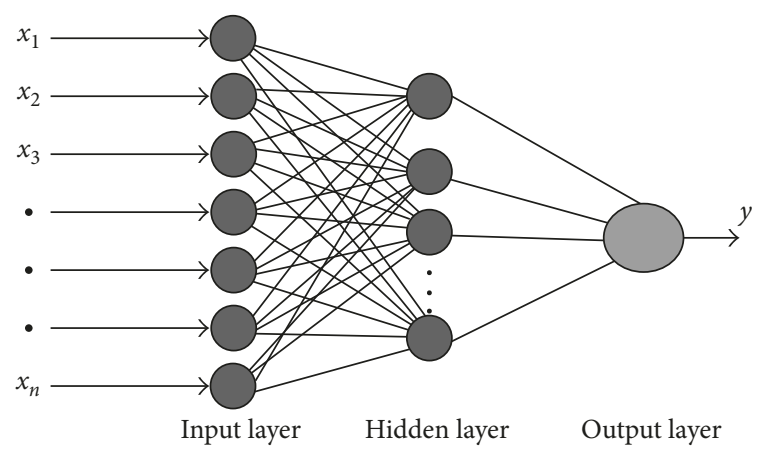

FIgURE 1: Structure of the NN model.

This function is minimized using the standard optimization method [37, 38].

In this work, a three-layer NN model is developed through which the compressive strength of concrete is predicted. In Figure 1, $x_{1}, x_{2}, x_{3} \ldots x_{n}$ are the input variables where $x_{1}$ is the water content, $x_{2}$ is the sand content, and $x_{3}$ is the coarse aggregates. For the prediction of 28-day compressive strength, three inputs $\left(x_{1}, x_{2}, x_{3}\right)$ are used, and $y$ (output) is the 28-day compressive strength of concrete. In case of prediction of 56-day compressive strength of concrete, four inputs $\left(x_{1}, x_{2}, x_{3}, x_{4}\right)$ are used where $x_{4}$ is the 28 -day curing compressive strength and used as the input for the prediction of 56-day compressive strength of concrete, and $y$ is the 56-day compressive strength of concrete. For the prediction of 91-day compressive strength of concrete, five inputs $\left(x_{1}, x_{2}, x_{3}, x_{4}, x_{5}\right)$ are used where $x_{4}$ is the 28-day curing compressive strength and used as the input for the prediction of compressive strength of concrete and $x_{5}$ is the 56-day curing compressive strength and used as the input for the prediction of 91-day compressive strength of concrete, and $y$ is the 91-day compressive strength of concrete [11].

\section{Results and Discussion}

Table 3 presents the results of training, validation, and testing datasets of the DT model, RF model, and NN model for prediction of compressive strength of concrete at the ages of 28, 56, and 91 days. Figures 2-10 show the graphical representation of results of training dataset, validation dataset, and testing dataset for the DT model, RF model, and $\mathrm{NN}$ model, respectively. It can be observed from these figures that the NN model and RF model have been predicted very close to the measured values of compressive strength of concrete. The DT model predicted its best, when the strength is at the curing age of 91 days. The values of coefficient of determination $\left(R^{2}\right)$ are $0.878,0.8835$, and 0.8270 for training, validation, and testing datasets, respectively, when compressive strength is at the curing age of 91 days. In this case, the minimum root-mean-square error (RMSE) is 1.7957 for validation dataset. It has been worked poorly, when the compressive strength is at the curing age of 28 days. In the prediction of compressive strength of concrete for the training dataset at age of 28 days, the value of $R^{2}$ is observed as 0.7167 with a RMSE of 3.0717 . The $R^{2}$
A 6-10-1 network with 87 weights.

Inputs: c, w, sand, ca, 28 days compressive strength, 56 days compressive strength.

Output: 91 days compressive strength.

Sum of Squares Residuals: 21.2436.

NN build options: skip-layer connections; linear output units.

In the following table:

b represents the bias associated with a node

h1 represents hidden layer node 1

i1 represents input node 1 (i.e., input variable 1)

o represents the output node

Weights for node hl:

b->h1 i1->h1 i2->h1 i3->h1 i4->h1 i5->h1 i6->h1

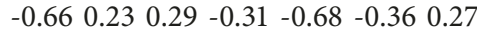

Weights for node h2:

b->h2 i1->h2 i2->h2 i3->h2 i4->h2 i5->h2 i6->h2

$1.37-2.30-14.017 .40-0.1922 .80-20.86$

Weights for node h3:

b->h3 i1->h3 i2->h3 i3->h3 i4->h3 i5->h3 i6->h3

$0.390 .25-0.16-0.55-0.520 .25-0.65$

Weights for node h4:

b->h4 i1->h4 i2->h4 i3->h4 i4->h4 i5->h4 i6->h4

$-0.47-0.16-40.5414 .61-1.09-0.8135 .27$

Weights for node h5:

b->h5 i1->h5 i2->h5 i3->h5 i4->h5 i5->h5 i6->h5

$\begin{array}{lllllllll}0.56 & 0.44 & 0.41 & 0.51 & 0.38 & 0.22 & 0.47\end{array}$

Weights for node h6:

b->h6 i1->h6 i2->h6 i3->h6 i4->h6 i5->h6 i6->h6

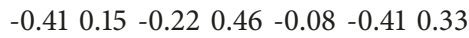

Weights for node h7:

b->h7 i1->h7 i2->h7 i3->h7 i4->h7 i5->h7 i6->h7

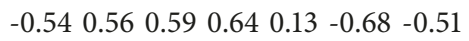

Weights for node h8:

b->h8 i1->h8 i2->h8 i3->h8 i4->h8 i5->h8 i6->h8

$\begin{array}{lllllll}0.55 & 0.05 & 0.15 & 0.31 & -0.15 & 0.24 & 0.02\end{array}$

Weights for node h9:

b->h9 i1->h9 i2->h9 i3->h9 i4->h9 i5->h9 i6->h9

$\begin{array}{lllllll}0.33 & -0.44 & -0.47 & -0.68 & 0.07 & 0.30 & 0.35\end{array}$

Weights for node h10:

b->h10 i1->h10 i2->h10 i3->h10 i4->h10 i5->h10 i6->h10

$\begin{array}{lllllll}-0.01 & 0.09 & 0.65 & -0.36 & -0.41 & -0.56 & 0.50\end{array}$

Weights for node o:

b->o h1->o h2->o h3->o h4->o h5->o h6->o h7->o h8->o

h9->o h10->o

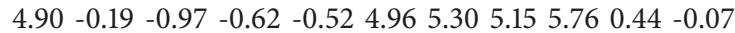

i1->o i2->o i3->o i4->o i5->o i6->o

$\begin{array}{llllll}0.09 & -0.22 & 0.02 & 0.00 & 0.06 & 0.42\end{array}$

Algorithm 3: Summary of the neural network model architecture (built using nnet) [39].

value is lower than 0.8 , which is generally not considered as a good fit. The DT model has not been suited for the validation and testing datasets as the value of $R^{2}$ is too low (0.4534 and 0.4388 , resp.). The problem with the DT model is that it is unable to predict beyond the range (minimum and maximum limits) given in the training dataset; therefore, the RMSE is high as compared to RF and NN. One of the gigantic pros of a RF model is that there is only one hyperparameter to tune, that is, the number of trees. On the other 
TABLE 3: Results of training and validation of the DT model, RF model, and NN model for compressive strength of concrete.

\begin{tabular}{|c|c|c|c|c|c|c|c|}
\hline \multirow{2}{*}{ Model } & \multirow{2}{*}{ Curing age } & \multicolumn{2}{|c|}{ Results of training set } & \multicolumn{2}{|c|}{ Results of validation set } & \multicolumn{2}{|c|}{ Results of testing set } \\
\hline & & $R^{2}$ & RMSE & $R^{2}$ & RMSE & $R^{2}$ & RMSE \\
\hline \multirow{3}{*}{ DT } & 28 days & 0.7167 & 3.0717 & 0.4534 & 3.7188 & 0.4388 & 3.9073 \\
\hline & 56 days & 0.8604 & 2.0111 & 0.7519 & 2.4596 & 0.8008 & 2.2514 \\
\hline & 91 days & 0.8785 & 1.8454 & 0.8835 & 1.7957 & 0.8270 & 1.8294 \\
\hline \multirow{3}{*}{$\mathrm{RF}$} & 28 days & 0.9426 & 1.6433 & 0.7943 & 1.3400 & 0.6870 & 2.6912 \\
\hline & 56 days & 0.9670 & 1.1306 & 0.9343 & 1.7282 & 0.9058 & 1.1449 \\
\hline & 91 days & 0.9780 & 0.8957 & 0.9828 & 1.6123 & 0.9213 & 1.0700 \\
\hline \multirow{3}{*}{$\mathrm{NN}$} & 28 days & 0.9599 & 0.7251 & 0.9476 & 0.8213 & 0.9460 & 0.8106 \\
\hline & 56 days & 0.9769 & 0.7176 & 0.9872 & 0.8099 & 0.9500 & 0.9100 \\
\hline & 91 days & 0.9770 & 0.8023 & 0.9824 & 0.9641 & 0.9562 & 0.9106 \\
\hline
\end{tabular}

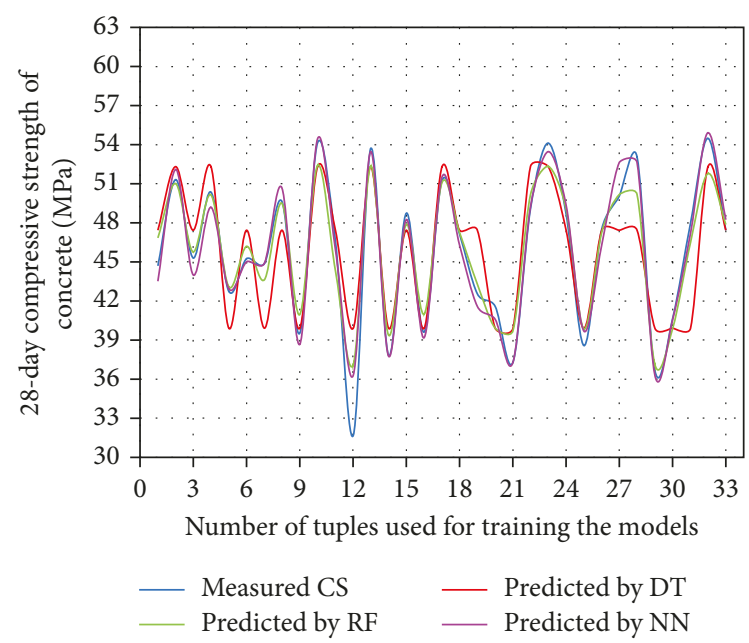

FIGURE 2: Comparison between predicted and actual values of 28-day compressive strength of concrete during training using DT, $\mathrm{RF}$, and NN models.

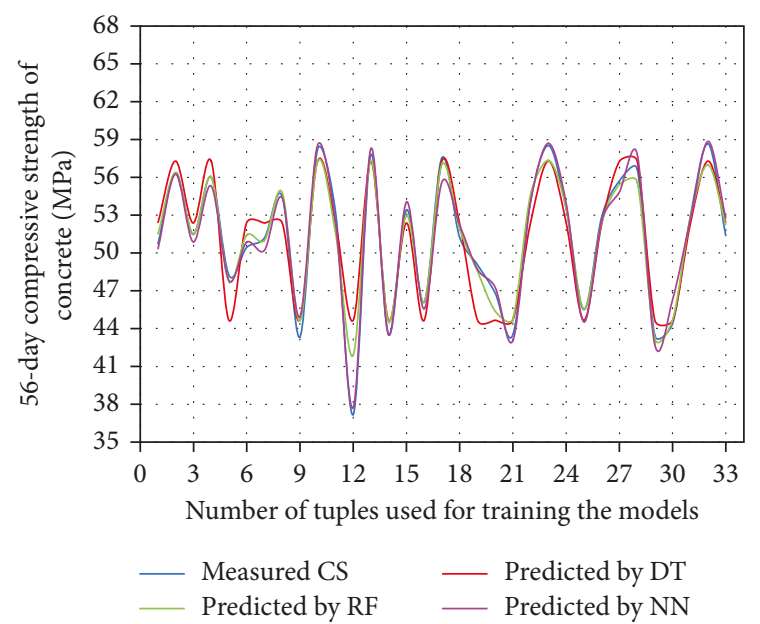

FIGURE 3: Comparison between predicted and actual values of 56-day compressive strength of concrete during training using DT, $\mathrm{RF}$, and NN models.

hand, in an NN model, there are a number of hyperparameters need to be tuned, for example, number of hidden layers, number of hidden layer neurons, initial weights, and

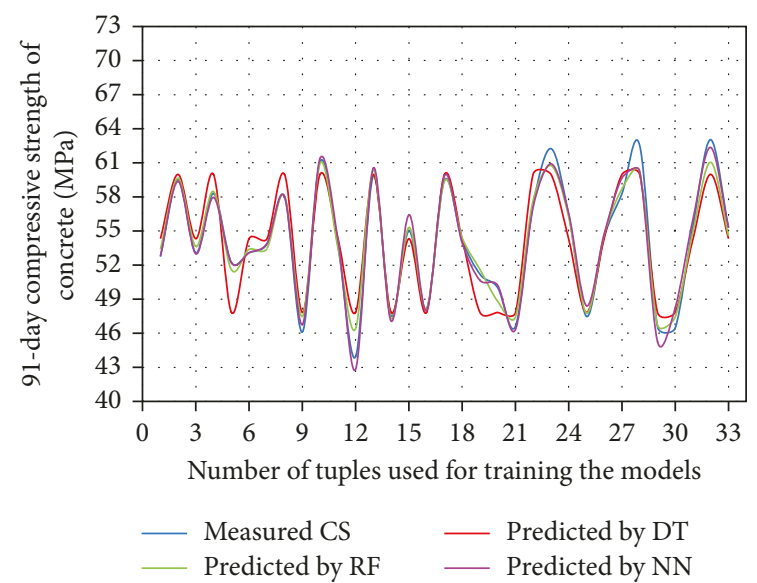

FIgURE 4: Comparison between predicted and actual values of 91-day compressive strength of concrete during training using DT, $\mathrm{RF}$, and NN models.

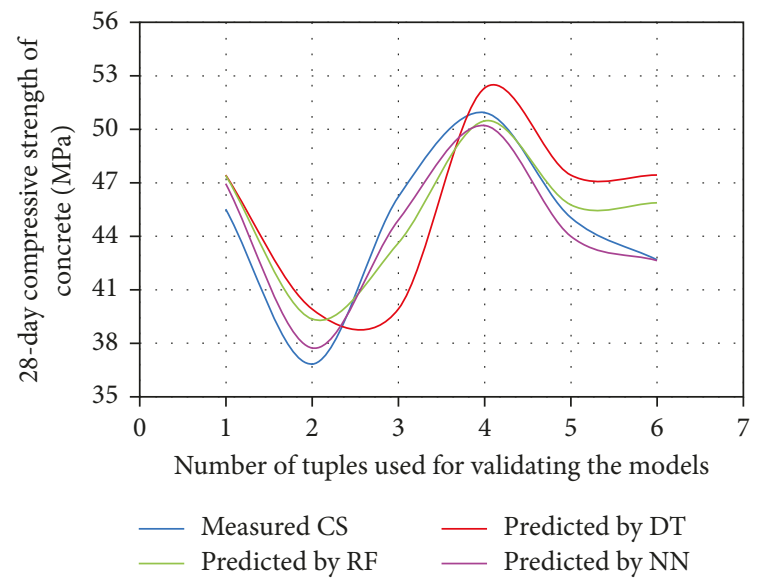

FIgURE 5: Comparison between predicted and actual values of 28-day compressive strength of concrete during validating the models using DT, RF, and NN models.

epochs. The RF model has been predicted very satisfactorily for the present dataset (except for two cases validation and testing datasets of 28-day compressive strength of concrete); it is greater than 0.9058 in all other cases. 


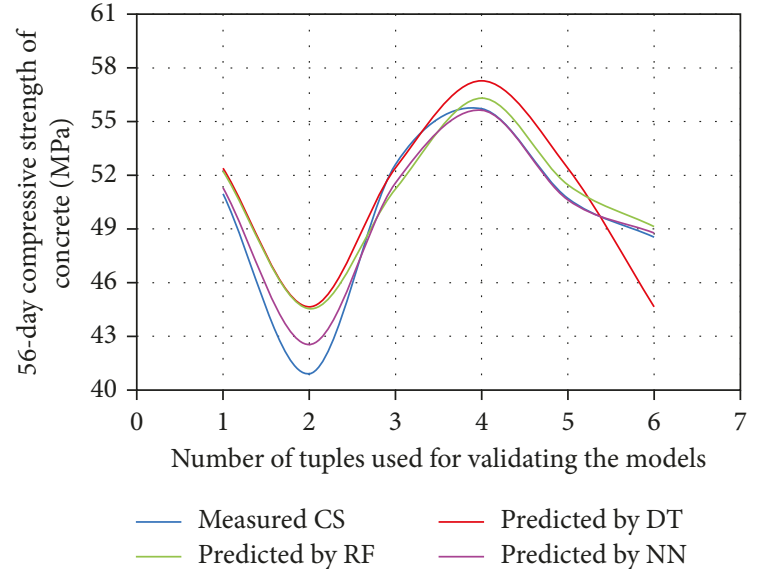

FIGURE 6: Comparison between predicted and actual values of 56-day compressive strength of concrete during validating the models using DT, RF, and NN models.

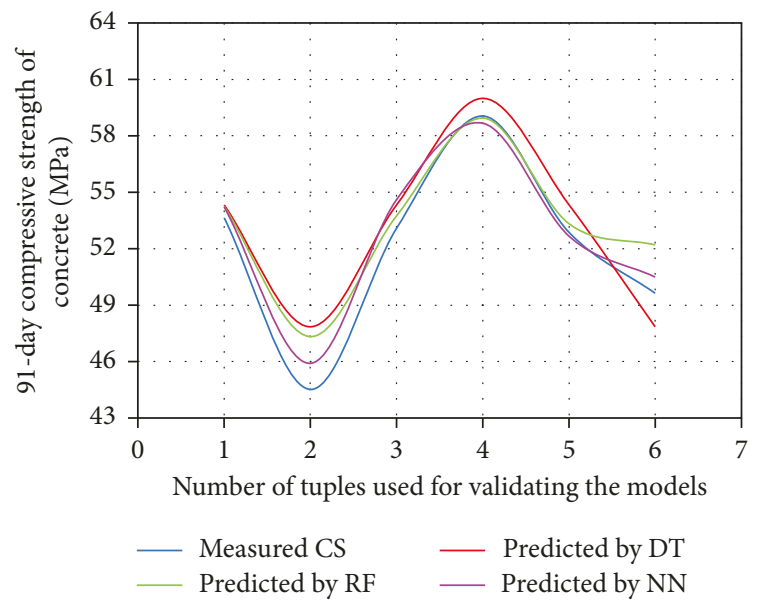

Figure 7: Comparison between predicted and actual values of 91-day compressive strength of concrete during validating the models using DT, RF, and NN models.

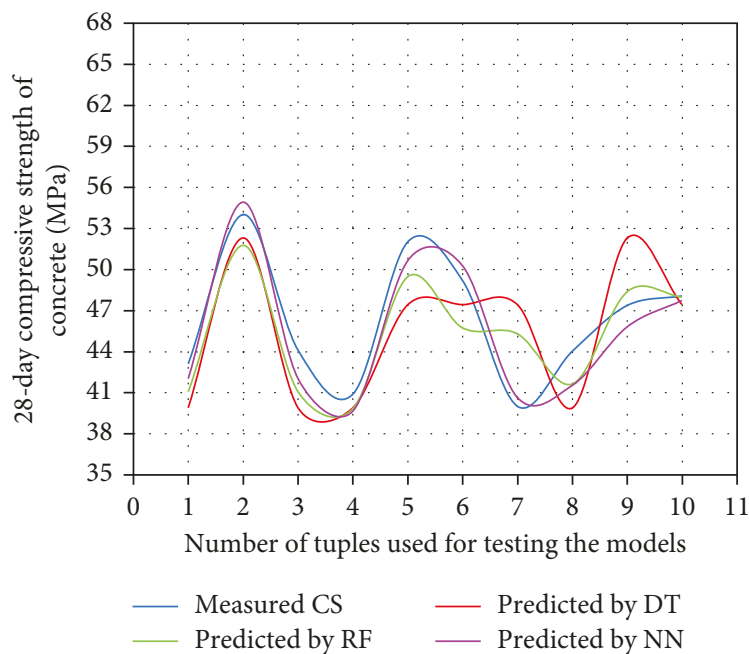

Figure 8: Comparison between predicted and actual values of 28-day compressive strength of concrete during testing the models using DT, RF, and NN models.

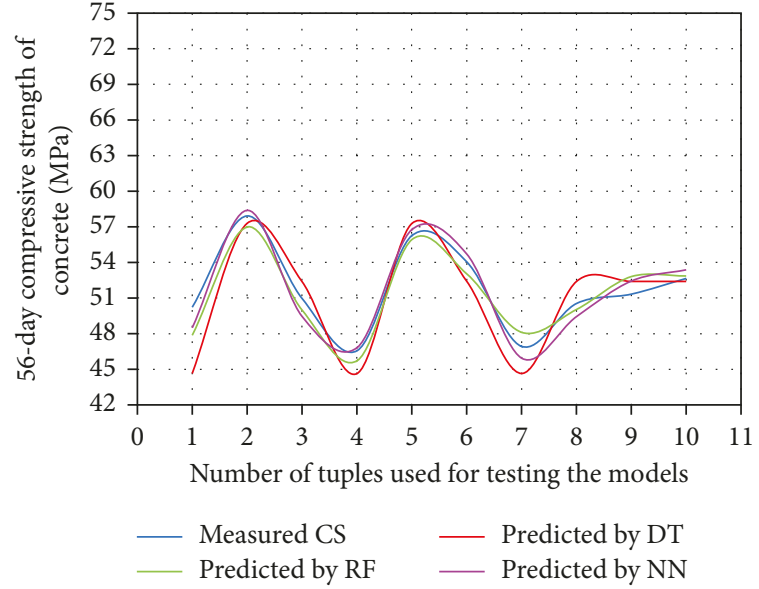

FIgURE 9: Comparison between predicted and actual values of 56-day compressive strength of concrete during testing the models using DT, RF, and NN models.

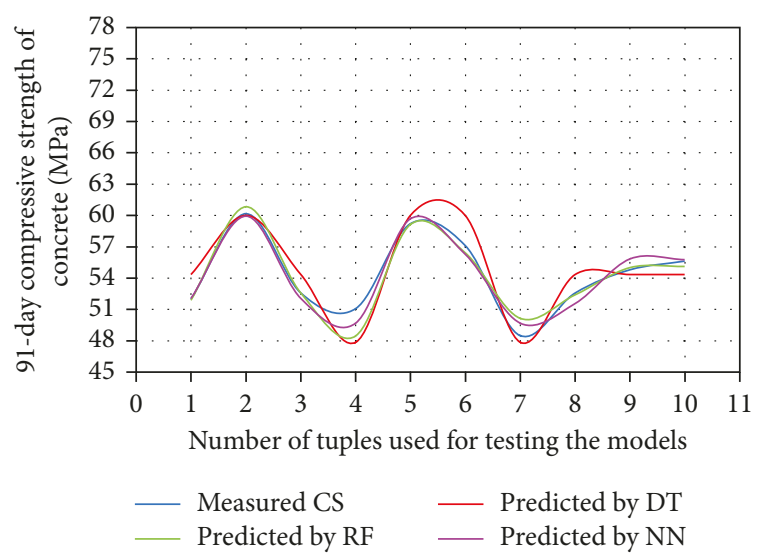

FIgURE 10: Comparison between predicted and actual values of 91-day compressive strength of concrete during testing the models using DT, RF, and NN models.

In the present study, the best prediction has been done by the NN model (as concluded in [13] also, when it was compared with GP). One of the foremost benefits of NN as compared to RF and DT models is that NN can approximate highly nonlinear functions between input-output features and require no prior knowledge of the nature of that relationship. For the present study, it has been predicted with the value of $R^{2} \geq 0.9460$ (in case of testing dataset of 28-day compressive strength of concrete) and the value of RMSE (for NN model) is less than 1. The maximum RMSE is 0.9641 for the validation dataset of 91-day compressive strength of concrete. The RF model for 28-day compressive strength of concrete has been predicted very close to the values of $R^{2}$ as of the NN model, but the value of RMSE of the RF model is at higher side in all curing ages.

\section{Conclusions}

(i) $\mathrm{NN}$ approaches combine the complexity of many statistical techniques with machine learning techniques and attributed as a black-box which allows 
$\mathrm{NN}$ to be applied in all engineering disciplines. It comes out as the best possible model for the prediction of compressive strength of concrete. It has predicted with high accuracy for all the curing ages, that is, 28, 56, and 91 days.

(ii) The RF model has been concluded as the second possible alternative for 56- and 91-day compressive strength of concrete, but it consumes longer time as compared to NN. The DT model has not been able to predict for the present dataset of compressive strength of concrete.

(iii) R" programming software environment is very helpful to programmers and nonprogrammer researchers for the statistical analysis of data.

(iv) As an outcome, the NN model may serve as the best feasible prediction tool for predicting the compressive strength of concrete.

\section{Conflicts of Interest}

The authors declare that they have no conflicts of interest regarding the publication of this paper.

\section{References}

[1] N. Hong-Guang and J. Zong Wang, "Prediction of compressive strength of concrete by neural networks," Cement and Concrete Research, vol. 30, no. 8, pp. 1245-1250, 2000.

[2] A. Baykasoglu, T. Dereli, and S. Tanis, "Prediction of cement strength using soft computing techniques," Cement and Concrete Research, vol. 34, no. 11, pp. 2083-2090, 2004.

[3] S. Akkurt, G. Tayfur, and S. Can, "Fuzzy logic model for the prediction of cement compressive strength," Cement and Concrete Research, vol. 34, no. 8, pp. 1429-1433, 2004.

[4] A. Oztas, M. Pala, E. Ozbay, E. Kanca, N. Caglar, and M. A. Bhatti, "Prediciting the compressive strength and slump of high strength concrete using neural network," Construction and Building Materials, vol. 20, no. 9, pp. 769-775, 2006.

[5] M. Pala, E. Ozbay, A. Oztas, and M. I. Yuce, "Appraisal of long term effects of fly ash and silica fume on compressive strength of concrete by neural networks," Construction and Building Materials, vol. 21, no. 2, pp. 384-394, 2007.

[6] N. P. Rajamane, J. A. Peter, and P. S. Ambily, "Prediction of compressive strength of concrete with fly ash as sand replacement material," Cement and Concrete Composites, vol. 29, no. 3, pp. 218-223, 2007.

[7] M. Ozturan, B. Kutlu, and T. Ozturan, "Comparison of concrete strength prediction techniques with artificial neural network approach," Building Research Journal, vol. 56, pp. 23-36, 2008.

[8] M. M. Alshihri, M. A. Azmy, and M. S. El-Bisy, "Neural networks for predicting compressive strength of structural light weight concrete," Construction and Building Materials, vol. 23, no. 6, pp. 2214-2219, 2009.

[9] M. Saridemir, "Prediction of compressive strength of concretes containing metakaolin and silica fume by artificial neural networks," Advances in Engineering Software, vol. 40, no. 5, pp. 350-355, 2009.

[10] M. A. Diab, E. H. Elyamany, A. E. M. A. Elmoaty, and H. A. Shalan, "Prediction of concrete compressive strength due to long term sulfate attack using neural network," Alexandria Engineering Journal, vol. 53, no. 3, pp. 627-642, 2014.

[11] P. Chopra, R. K. Sharma, and M. Kumar, "Artificial neural networks for the prediction of compressive strength of concrete," International Journal of Applied Sciences \& Engineering, vol. 13, no. 3, pp. 187-204, 2015.

[12] P. Chopra, R. K. Sharma, and M. Kumar, "Predicting compressive strength of concrete for varying workability using regression models," International Journal of Engineering \& Applied Sciences, vol. 6, no. 4, pp. 10-22, 2014.

[13] P. Chopra, R. K. Sharma, and M. Kumar, "Prediction of compressive strength of concrete using artificial neural network and genetic programming," Advances in Materials Science and Engineering, vol. 2016, Article ID 7648467, 10 pages, 2016.

[14] S. S. Wu, B. Z. Li, J. G. Yong, and S. K. Shukla, "Predictive modelling of high-performance concrete with regression analysis," in Proceedings of IEEE International Conference on Industrial Engineering and Engineering Management, pp. 1009-1013, Singapore, 2010.

[15] M. F. M. Zain and S. M. Abd, "Multiple regressions model for compressive strength prediction of high performance concrete," Journal of Applied Sciences, vol. 9, no. 1, pp. 155-160, 2009.

[16] M. S. Sayed Ahmed, "Statistical modelling and prediction of compressive strength of concrete," Concrete Research Letters, vol. 3, no. 2, pp. 452-458, 2012.

[17] H. Bayrak and F. Akgül, "Effect of coefficients of regression model on performance prediction curves," International Journal of Engineering and Applied Sciences, vol. 5, pp. 32-39, 2013.

[18] J. Namyong, Y. Sangchun, and C. Hongburm, "Prediction of compressive strength of in-situ concrete based on mixture proportions," Journal of Asian Architecture and Building Engineering, vol. 3, pp. 9-15, 2004.

[19] I. B. Topcu and M. Saridemir, "Prediction of compressive strength of concrete containing fly ash using artificial neural networks and fuzzy logic," Computational Materials Science, vol. 41, no. 3, pp. 305-311, 2008.

[20] C. Basyigit, I. Akkurt, S. Kilincarslan, and A. Beycioglu, "Prediction of compressive strength of heavyweight concrete by ANN and FL models," Neural Computing and Applications, vol. 19, no. 4, pp. 507-513, 2009.

[21] M. W. Wankhade and A. R. Kambekar, "Prediction of compressive strength of concrete using artificial neural network," International Journal of Scientific Research and Reviews, vol. 2, no. 2, pp. 11-26, 2013.

[22] S. Tiryaki and A. Aydin, "An artificial neural network model for predicting compressive strength of heat treated woods and comparison with a multiple linear regression model," Construction and Building Materials, vol. 62, pp. 102-108, 2014.

[23] M. Nikoo, F. T. Moghadam, and L. Sadowski, "Prediction of concrete compressive strength by evolutionary artificial neural networks," Advances in Materials Science and Engineering, vol. 2015, Article ID 849126, 8 pages, 2015.

[24] F. Khademi, M. Akbari, S. M. Jamal, and M. Nikoo, "Multiple linear regression, artificial neural network and fuzzy logic prediction of 28 days compressive strength of concrete," Frontiers of Structural and Civil Engineering, vol. 11, no. 1, pp. 90-99, 2017.

[25] A. Khashman and P. Akpinar, "Non-destructive prediction of concrete compressive strength using neural networks," Procedia Computer Science, vol. 108, pp. 2358-2362, 2017.

[26] M. Kumar, Reliability Based Design of Structural Elements, Ph.D. thesis, T.I.E.T, Patiala, India, 2002. 
[27] L. Yang, S. Liu, S. Tsoka, and L. G. Papageorgiou, "A regression tree approach using mathematical programming," Expert Systems with Applications, vol. 78, no. 5, pp. 347-357, 2017.

[28] Y. Song and Y. Lu, "Decision tree methods: applications for classification and prediction," Shanghai Archives of Psychiatry, vol. 27, no. 2, pp. 130-135, 2015.

[29] C. Kingsford and S. L. Salzberg, "What are decision trees?," Nature Biotechnology, vol. 26, no. 9, pp. 1011-1013, 2008.

[30] K. Fawagreh, M. M. Gaber, and E. Elyan, "Random forests: from early development to recent advancements," Systems Science \& Control Engineering, vol. 2, no. 1, pp. 602-609, 2014.

[31] M. D. M. Denil and F. Freitas, "Narrowing the gap: random forests in theory and practice," in Proceedings of 31st International Conference on Machine Learning, Beijing, China, June 2014.

[32] A. Shaqadan, "Prediction of concrete mix strength using random forest model," International Journal of Applied Engineering Research, vol. 11, no. 22, pp. 11024-11029, 2016.

[33] C. T. Altendorf, R. L. Elliott, E. W. Stevens, and M. L. Stone, "Development and validation of neural network model for soil water content prediction with comparison to regression techniques," Transactions of the American Society of Agricultural Engineering, vol. 42, no. 3, pp. 691-699, 1999.

[34] A. T. A. Dantas, M. B. Leite, and K. D. J. Nagahama, "Prediction of compressive strength of concrete containing construction and demolition waste using artificial neural networks," Construction and Building Materials, vol. 38, pp. 717-722, 2013.

[35] P. K. Simpson, Neural Networks, Theory, Technology, and Applications, IEEE Inc., New York, NY, USA, 1996.

[36] K. Knight, "Connectionist ideas and algorithms," Communications of the ACM, vol. 33, no. 11, pp. 59-74, 1990.

[37] J. A. Anderson, An Introduction to Neural Networks, The MIT Press, Cambridge, MA, USA, 1995.

[38] A. K. Sharma, I. K. Sawhney, and M. Lal, "Intelligent modeling and analysis of moisture sorption isotherms in milk and pearl millet based weaning food "Fortified Nutrimix"," Drying Technology, An International Journal, vol. 32, no. 6, pp. 728-741, 2014.

[39] J. Han, M. Kamber, and J. Pei, Data Mining: Concepts and Techniques, Morgan Kaufmann, Burlington, MA, USA, 3rd edition, 2012. 


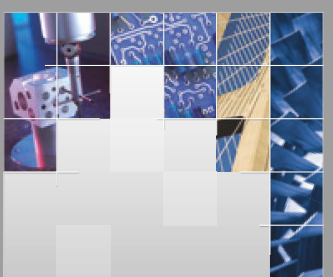

\section{Enfincering}
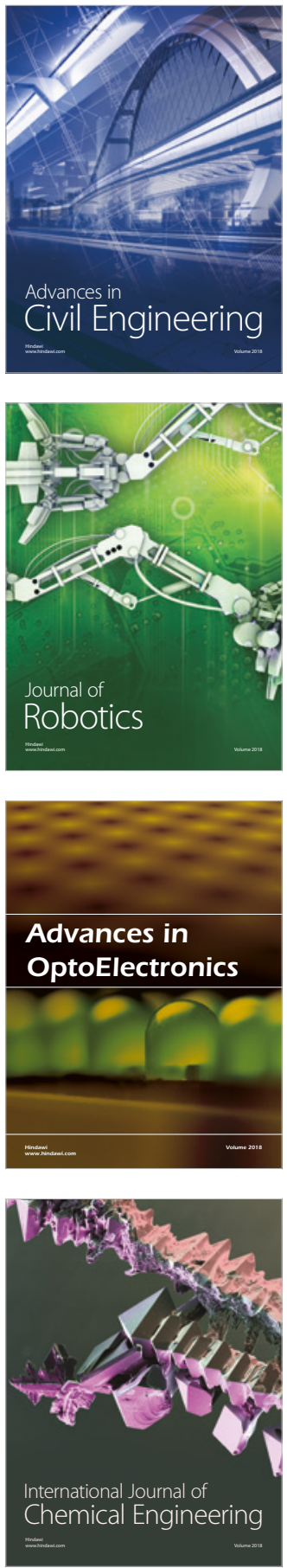

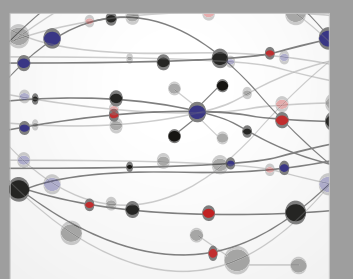

\section{Rotating \\ Machinery}

The Scientific World Journal

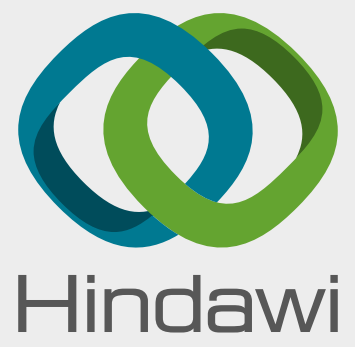

Submit your manuscripts at

www.hindawi.com
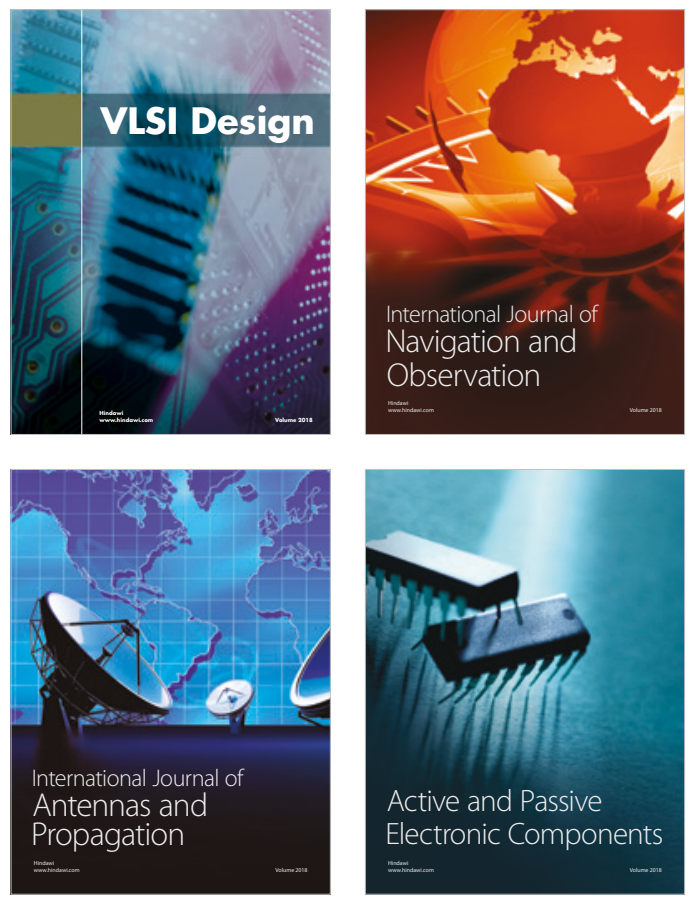
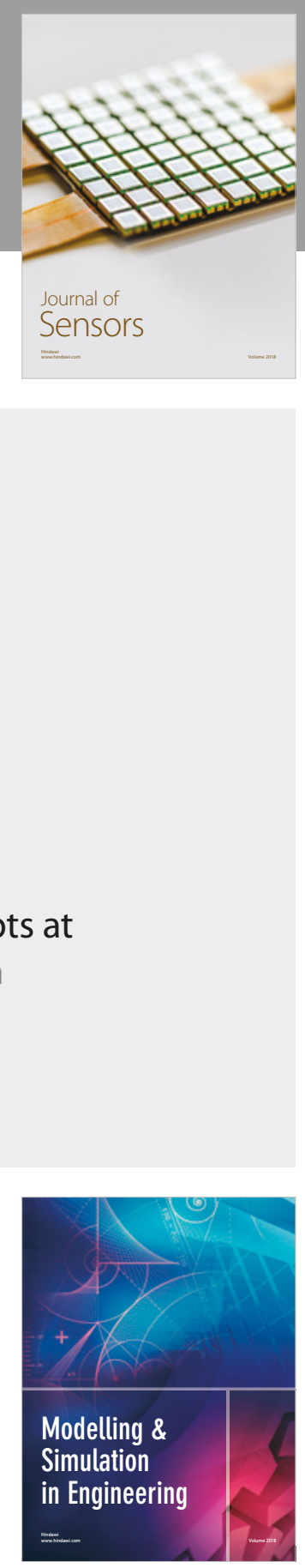

\section{Advances \\ Multimedia}
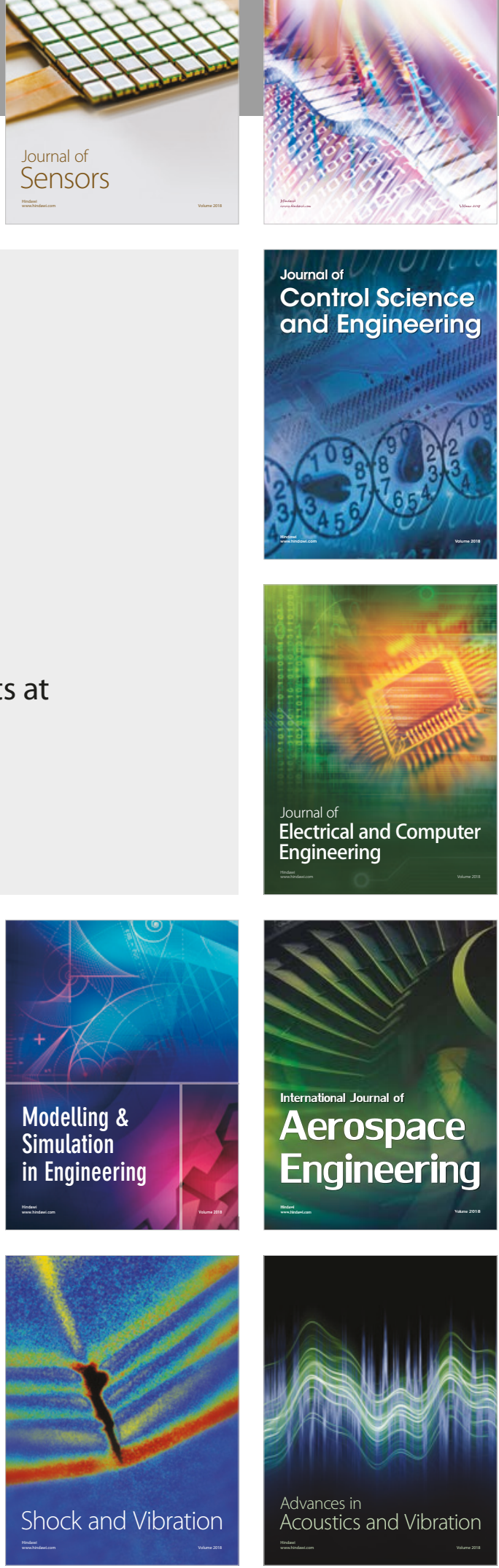